\title{
The Impending Epidemic of Cardiovascular Diseases in Patients With Cancer in Japan
}

\author{
Yuji Okura, MD, PhD; Kazuyuki Ozaki, MD, PhD; Hiroshi Tanaka, MD, PhD; \\ Tatsuya Takenouchi, MD, PhD; Nobuaki Sato, MD, PhD; Tohru Minamino, MD, PhD
}

\begin{abstract}
Onco-cardiology, a new academic field, aims to improve the quality of life and prognosis of cancer patients and survivors with cardiovascular diseases (CVD). With the aging of the population, an epidemic of cancer with CVD is emerging in developed countries. Cancer and CVD share risk factors, pathophysiology, treatments, and preventive and rehabilitative measures. A multidisciplinary team-based approach is needed to support cancer treatment to maximize its effectiveness and minimize its cardiotoxic potential. Basic and clinical onco-cardiology are already being practiced harmoniously. However, systematization in academia and clinical practice and accumulation of evidence have just started. In this review, we present the epidemiology, common risk factors between cancer and CVD, future epidemic of CVD in patients with cancer, and the necessity for an onco-cardiological approach to managing the burden of CVD in cancer patients and survivors.
\end{abstract}

Key Words: Cancer; Cardiovascular toxicities; Epidemiology; Onco-cardiology; Risk factors

$\mathbf{O}$ nco-cardiology is a new academic field that aims to improve the quality of life and prognosis of cancer patients and survivors with cardiovascular diseases (CVD). Cardiology and oncology have been considered separate medical fields for a long time, but advancements in cancer therapy in this decade have brought greater recognition of the perspectives of onco-cardiology in academia for both oncology and cardiology. Clinically, oncologists and cardiologists collaborate in the diagnosis and treatment of cancer patients with CVD. Through various studies, oncologists and cardiologists have noticed that cancer and CVD share some common pathological and risk factors, and an intervention in one affects the other. ${ }^{1-4}$ Subsequently, in 2018, a new chapter, cardio-oncology, was added to an authoritative textbook on cardiology, and there are more than 200 annual publications in this field on PubMed. ${ }^{5}$ Furthermore, the American College of Cardiology will start publishing JACC: CardioOncology in September 2019.

The majority of cardiologists may have less confidence regarding the treatment of CVD in patients with cancer because of the following questions: How long will the patient live? Is the treatment of CVD beneficial in patients with limited life expectancy? Will the treatment of CVD result in serious adverse effects, such as gastrointestinal bleeding or intracranial hemorrhage? Does the evidence from patients without cancer apply to those with cancer? When cardiologists are faced with these questions, oncologists may have the knowledge, experience, and perspective of the solutions. Similarly, when oncologists assess the risk and benefit of cancer therapies, cardiologists can assist them in evaluating the risk of CVD and identifying the best therapeutic approach. Therefore, the 2 fields - cardiology and oncology - should complement each other and not act as competitors. ${ }^{6}$

The Japanese Onco-cardiology Society was established in 2017 for better collaboration in the treatment of patients with cancer. A multidisciplinary, team-based approach is required to support the cancer treatment, prevent CVD as a complication, and balance the treatments for cancer and CVD. Clinical onco-cardiology is already being practiced harmoniously. However, academic systematization and accumulation of evidence have only just started. Therefore, in this review, we present the epidemiology, common risk factors between cancer and CVD, future epidemic of CVD in patients with cancer, and the necessity for an onco-cardiological approach to managing the burden of CVD in cancer patients and survivors.

\section{Attracting Attention to Onco-Cardiology Increasing Numbers of Elderly Patients With Cancer} The proportion of elderly patients in the cancer registry has increased in line with the aging of the population in Japan. Approximately $36 \%$ of patients were older than 75 years in 2015 and that proportion is estimated to increase annually. ${ }^{7}$ Elderly patients with cancer tend to have multiple comorbidities and organ dysfunctions, which increases the

Received May 17, 2019; revised manuscript received July 22, 2019; accepted August 19, 2019; J-STAGE Advance Publication released online September 18, 2019

Department of Onco-cardiology (Y.O.), Department of Respiratory Medicine (H.T.), Department of Dermatology (T.T.), Department of Breast Oncology (N.S.), Niigata Cancer Center Hospital, Niigata; Department of Cardiovascular Biology and Medicine, Niigata University Graduate School of Medical and Dental Sciences, Niigata (K.O., T.M.), Japan

Mailing address: Yuji Okura, MD, PhD, Department of Onco-cardiology, Niigata Cancer Center Hospital, 2-15-3 Kawagishicho, Chuo-ku, Niigata 951-8560, Japan. E-mail: okuray@niigata-cc.jp

ISSN-1346-9843 All rights are reserved to the Japanese Circulation Society. For permissions, please e-mail: cj@j-circ.or.jp 

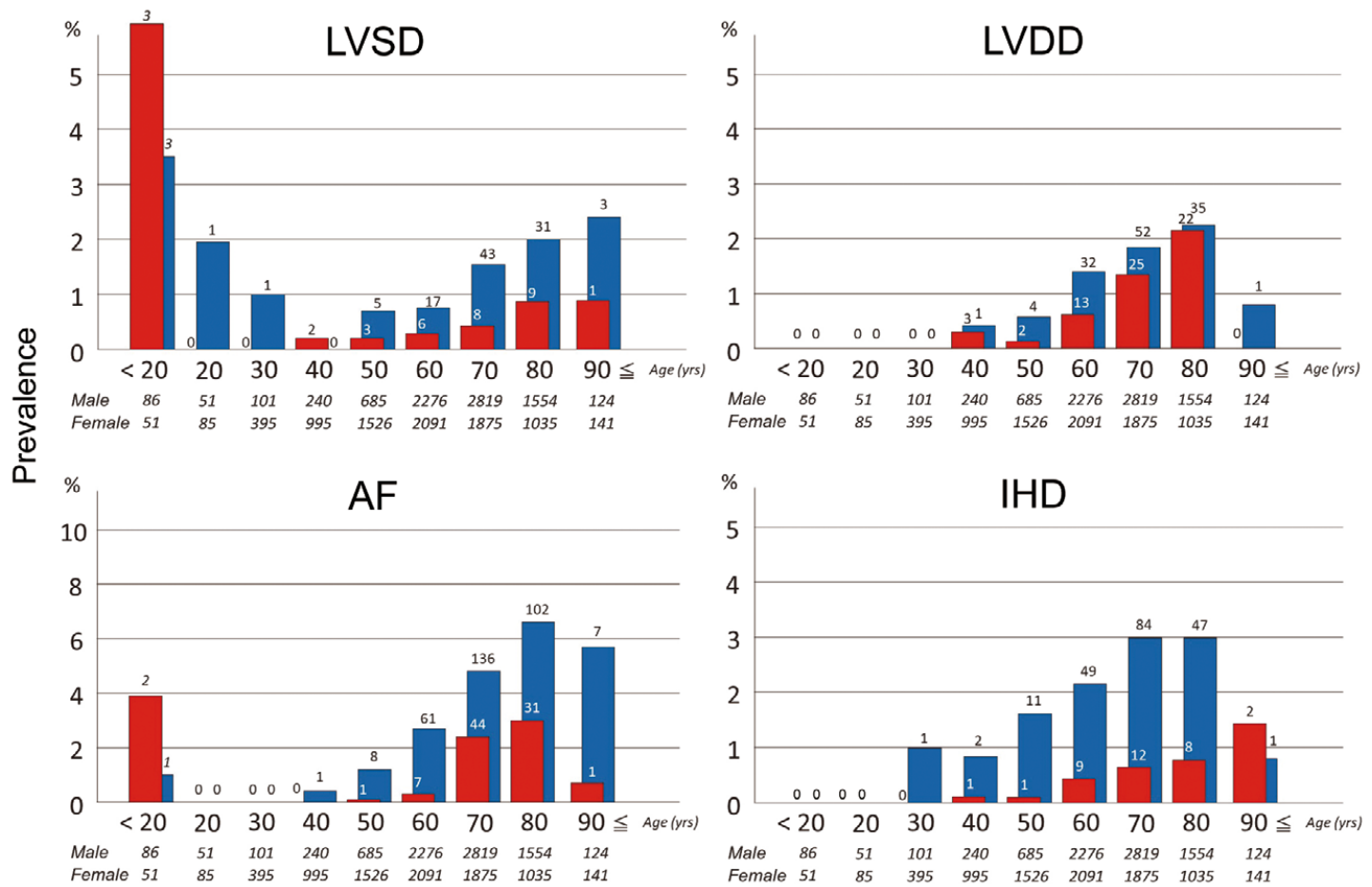

Cancer patients stratified by age and gender $(n=16,130)$
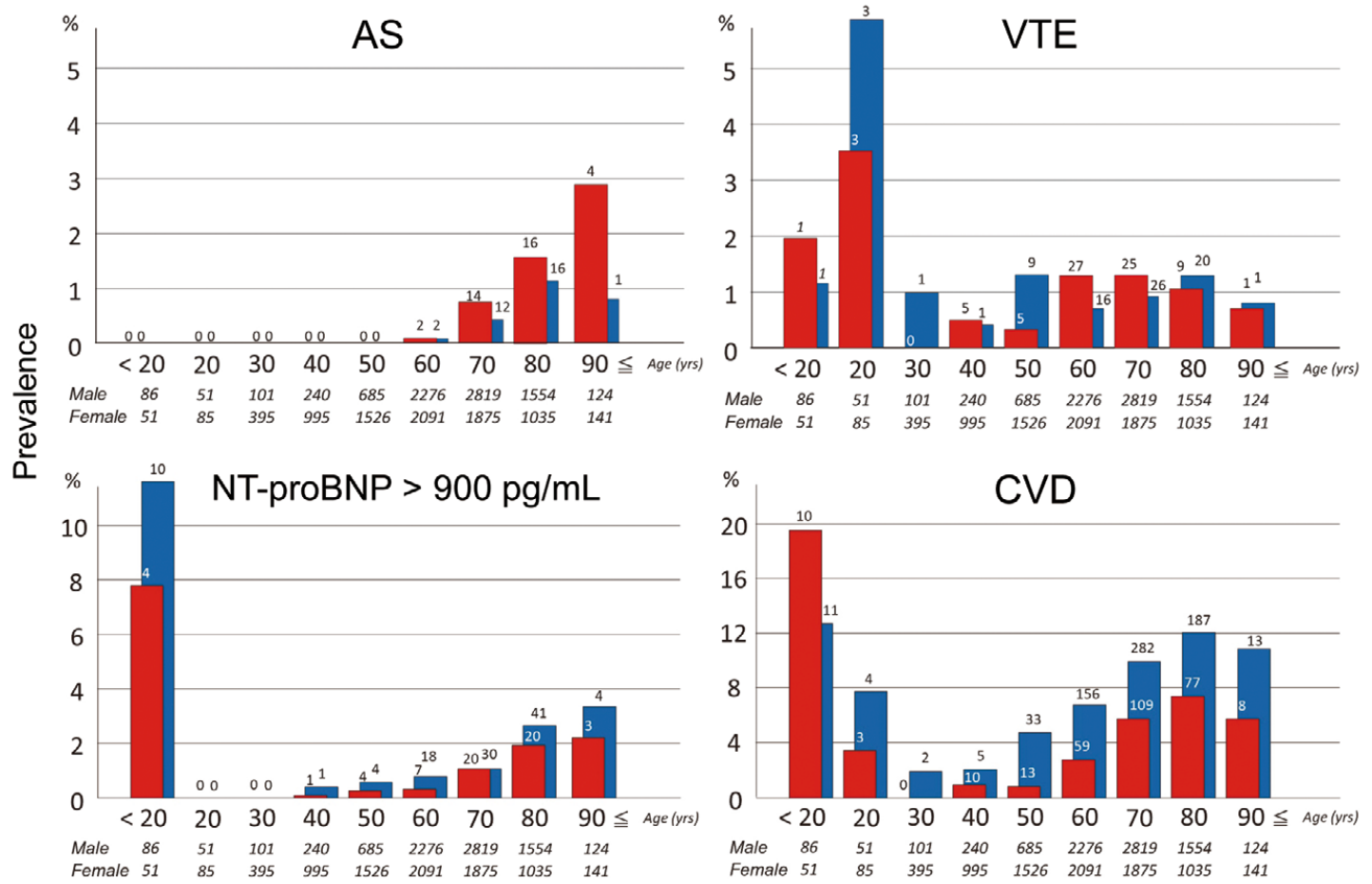

Cancer patients stratified by age and gender $(n=16,130)$

Figure 1. Prevalence of cancer patients with cardiovascular disease (CVD) in different age groups. The number shown at the upper end of each bar represents the count of patients with CVD, and the number below each age range along the horizontal axis represents the male and female patients with cancer for that range. AF, atrial fibrillation; AS, aortic stenosis; IHD, ischemic heart disease; LVDD, left ventricular diastolic dysfunction; LVSD, left ventricular systolic dysfunction; NT-proBNP, N-terminal pro-B-type natriuretic peptide; VTE, venous thromboembolism. Reproduced with permission from reference no. 11. 
incidence and severity of the side effects of cancer therapies. ${ }^{8}$ In particular, CVD is common in the elderly population; the prevalence of cardiac dysfunction in the general population in their $70 \mathrm{~s}$ reached $3.7 \%$ for men and $1.6 \%$ for women according to the Sado Heart Failure Study. ${ }^{9}$ Cancer care providers should be trained to recognize CVD and provide any necessary interventions concurrently with the cancer therapy.

\section{Epidemic of CVD in Patients With Cancer}

Hypertension, atrial fibrillation (AF), ischemic heart disease (IHD), venous thromboembolism (VTE), left ventricular dysfunction (LVD), and heart failure (HF) are common comorbidities in patients with cancer. ${ }^{10-12}$ Navi et al ${ }^{13}$ reported that patients with newly diagnosed cancer faced a considerably increased short-term risk of arterial thromboembolism. Within 6 months of diagnosis, more than twice as many patients with cancer had experienced arterial thromboembolism as matched controls without cancer.

We evaluated the prevalence of CVD in Japanese cancer patients and survivors using the cancer registry and CVD database in a 10-year period (2005-2014). ${ }^{11}$ The prevalence of CVD in cancer survivors in 2015 was $8.7 \%$ and $3.5 \%$ in males and females, respectively. AF was the most common CVD (prevalence: males, $4.0 \%$; females, $1.0 \%$ ). The prevalence of most CVDs in adults increased progressively with age, with male predominance $(12.1 \%$ in male and $7.5 \%$ in female patients in their $80 \mathrm{~s}$ ) (Figure 1). This is attributable to the common risk factors for cancer and CVD (e.g., aging, smoking, diabetes, obesity, and physical inactivity), neoplastic effects on the cardiovascular system, chemotherapy- and radiotherapy-induced cardiovascular toxicities, and longer life expectancies.,14-17

\section{CVD as a Clinical Manifestation of Cancer}

There are numerous reports of CVD as the initial manifestation of cancer. ${ }^{18-21}$ Navi et al examined the populationbased Surveillance, Epidemiology, and End Results-Medicare linked dataset and reported that within 30 days immediately before cancer diagnosis, $0.62 \%$ of patients and $0.11 \%$ of controls were diagnosed with myocardial infarction or ischemic stroke [odds ratio: $5.63 ; 95 \%$ confidence interval (CI): 5.07-6.25]. ${ }^{18}$ Vinter et al demonstrated that new-onset AF was associated with a subsequent increased risk of cancer in the Danish Diet, Cancer, and Health cohort, a population-based cohort in Denmark. Within the initial 90 days following the diagnosis of AF, the risk of any type of cancer was 3-4-fold higher than similar risk in patients without AF. ${ }^{19}$ Therefore, cardiologists can expect a diagnosis of cancer in their patients in the acute or chronic phase of CVD.

\section{Increasing Numbers of Cancer Survivors With CVD}

The Japanese Association of Clinical Cancer Centers reported a 10-year relative survival rate of $56 \%$ in $2019 . .^{22}$ Advancements in cancer care have increased the number of cancer survivors who could develop latent cardiac adverse effects secondary to cancer treatment. ${ }^{23}$ Antineoplastic agents adversely affect both the heart and vessels. Anthracyclines, cyclophosphamide, cisplatin, fluorouracil, trastuzumab, bevacizumab, and lenvatinib are commonly used in cancer therapy. Despite significant progress in cancer therapies, cardiovascular toxicities remain a concern. $., 6,23,24$ Therefore, cancer therapies have increased the prevalence of CVD. Previously, cardiovascular complications were not prevalent in patients with cancer because their life expectancies were often too short for complications to manifest. However, recently, cancer-patient survivability has increased, with some survivors developing chemotherapyrelated cardiovascular dysfunction., 5,6,23-25

\section{Poor Prognosis of Cancer Survivors With CVD}

There is a growing concern that cancer therapies may lead to premature morbidity and death from CVD among survivors. Armenian et al ${ }^{26}$ examined 36,232 adult cancer patients who survived for more than 2 years and 73,545 matched controls without cancer using the database in Kaiser Permanente Southern California, one of the biggest healthcare organization in the US. Survivors of multiple myeloma (incidence rate ratio [IRR], 1.70), carcinoma of the lung/bronchus (IRR, 1.58), non-Hodgkin's lymphoma (IRR, 1.41), and breast cancer (IRR, 1.13) had significantly higher CVD risk when compared with the controls. The 8 -year overall survival was significantly worse in cancer survivors who developed CVD $(60 \%)$ when compared with cancer survivors without CVD (81\%). In our registry, the 5 -year survival rate was $64.0 \%$ in all patients with cancer and $44.2 \%$ in cancer patients with CVD. ${ }^{11}$ Cox proportional hazards analysis, after adjusting for age, cancer stage, and body mass index, revealed that the following were significantly associated with death: AF [hazard ratio (HR): 1.219, male sex; $\mathrm{P}=0.038$ ], VTE (HR: 1.517 , male; $\mathrm{P}=0.003$; and HR: 2.089, female; $\mathrm{P}<0.001$ ), and $\mathrm{N}$-terminal pro-Btype natriuretic peptide elevation $>900 \mathrm{pg} / \mathrm{mL}$ (HR: 1.861 , female sex; $\mathrm{P}=0.002$ ). The outcomes for cancer survivors with CVD are poor; therefore, strategies for the prevention, early detection, palliation, and treatment of CVD need to be investigated.

\section{Common Risk Factors Between Cancer and CVD}

Aging, smoking, diabetes, obesity, and physical inactivity are risk factors for both cancer and CVD.,2,3,12,27,28 Therefore, patients with cancer often have cardiovascular comorbidities, and patients with CVD often have cancer. Some of these risk factors are targeted in cancer prevention. A combination of 5 healthy lifestyle factors (not smoking, moderate drinking, minimal ingestion of salt-preserved foods, being physically active, and having appropriate body mass index) was reported to be associated with a reduction in cancer risk in the US ${ }^{27}$ and in Japan. ${ }^{28}$ Sasazuki et al reported that adherence to $2,3,4$, and 5 healthy factors proportionally reduced the risk of cancer when compared with 0 or 1 factor. ${ }^{28}$ The risk decreased by $14 \%$ and $9 \%$ for each healthy lifestyle modification in men and women, respectively, and the maximum reduction was $43 \%$ and $37 \%$, respectively. Cancer and CVD appear to partially share their pathologies and their shared biology has been researched. $2,3,12,27-57$

\section{Shared Pathophysiology Between Cancer and CVD}

Smoking Nicotine is a common pathway in the pathogenesis of both CVD and cancer. Physiologically, nicotine increases blood pressure and clotting tendency via activation of the sympathetic nervous system and thromboxane $\mathrm{A}_{2}$, respectively. Nicotine is highly addictive and smoking results in atherosclerosis and left ventricular hypertrophy, leading to CVD. ${ }^{29}$ Moreover, smoking causes incessant inhalation of a complex mixture of chemicals, among which at least 70 are carcinogens (e.g., polycyclic aromatic hydrocarbons and tobacco-specific $\mathrm{N}$-nitrosamines). Many 
of these are thought to circulate and cause cancer by inducing DNA damage, which, if uncorrected, leads to somatic mutations and the risk of acquiring driver mutations in cancer genes. ${ }^{30}$ Oxidative stress by free radicals is another common pathogen in both atherosclerosis and cancer; oxidative stress results in endothelial damage and DNA damage. ${ }^{29,30}$

Obesity Obesity is associated with abnormalities in the secretion of adipokines. ${ }^{31,32}$ Increased secretions of inflammatory cytokines (e.g., tumor necrosis factor [TNF]- $\alpha$, interleukin [IL]-1 $\beta$, IL-6), adipokines, angiotensinogen, and plasminogen activator inhibitor-1 and decreased secretion of adiponectin result in chronic inflammation and thrombogenesis., 2,31,32 Both atherosclerosis and cancer result from incessant hyperinsulinemia and increased insulin-like growth factor (IGF) signaling, which promote cell differentiation and proliferation. ${ }^{33,34}$ Although the evidence for the role of insulin and IGF signaling is moderate, the evidence for the role of sex hormone metabolism and chronic inflammation in mediating the obesity-cancer relationship is strong. ${ }^{34}$ Estrogen produced by adipose tissue increases the risk of uterine cancer and breast cancer in postmenopausal women. ${ }^{35}$ Furthermore, there is convincing evidence that intentional body weight loss positively affects these mechanisms. ${ }^{27,28,35,36}$

Diabetes Diabetes accelerates atherosclerosis, and atherosclerotic factors are believed to promote carcinogenesis. ${ }^{37}$ Type 2 diabetes is associated with insulin resistance, hyperinsulinemia, and increased production of IGF. ${ }^{38}$ These are cell proliferation factors; therefore, carcinogenesis and cancer growth are induced by enhanced growth signals and suppressed apoptosis. Furthermore, mitochondrial dysfunction in hyperglycemia induces oxidative stress, which increases the risk of carcinogenesis. ${ }^{39}$

Comprehensive assessment of the association between preexisting diabetes and cancer risk based on a pooled analysis in Japan demonstrated a significantly higher risk of cancer of the colon (HR: 1.40), liver (HR: 1.97), pancreas (HR: 1.85), and bile duct (HR: 1.66; men only). Diabetes was associated with an overall $20 \%$ increased risk in the total cancer incidence in the Japanese population. ${ }^{40}$

According to a recent report of a Mendelian randomization study with a large number of incident cancer cases, no strong evidence supporting the association between diabetes and overall and site-specific cancer risks was found. ${ }^{\mathbf{4}}$ Furthermore, there is little evidence to support the genetic role of type 2 diabetes in cancer development in the Japanese population, although reverse causality and residual confounding by common risk factors could exist, and phenotypic diabetes remains an important target for cancer prevention and management by controlling lifestyle factors. Studies that investigate the risk factors for diabetes remain important.

Hypertension Hypertension is a well-established risk factor for CVD. Long-term endothelial injury from mechanical stress, chemical stress, glucotoxicity, dyslipidemia, oxidative stress, and radiation results in chronic inflammation and, consequently, atherosclerosis. However, observational studies that assessed hypertension and cancer risk have reported inconsistent results. A pooled collaborative analysis of 86,593 participants in 12 Australian and New Zealand cohorts identified 12,070 incident and 4,350 fatal cancer cases over a median follow-up of 15.1 years; untreated and treated hypertension, compared with normotension, was associated with an increased risk of cancer incidence (HR: 1.06, 95\% CI: 1.00-1.11 and HR: 1.09, 95\% CI: $1.02-1.16$, respectively) and cancer mortality (HR: 1.07, 95\% CI: $0.98-1.18$ and HR: $1.15,95 \%$ CI: $1.03-1.28$, respectively). ${ }^{42}$ The Metabolic Syndrome and Cancer Project, the largest study to date, assessed 7 population-based cohorts with 577,799 individuals from Norway, Austria, and Sweden for 12 years and found that men had a total incident cancer HR of 1.07 (95\% CI: 1.04-1.09) per $10 \mathrm{mmHg}$ increment in blood pressure, whereas women showed no such association. ${ }^{43}$ Angiotensin II and vascular endothelial growth factor may potentiate the development or progression of cancer and atherosclerosis, which may account for the association. ${ }^{2}$

Aging The incidence of cancer and CVD increases with advancing age. Aging is the most universal risk factor in both cancer and CVD. ${ }^{44}$ Senescence-associated $\beta$-gal activity is increased in the endothelial cells of coronary arteries in patients with coronary artery disease (CAD), and endothelial dysfunction is associated with a lack of nitric oxide synthesis and inflammation..$^{45}$ The numbers of these abnormal endothelial cells increase with advancing age. Vascular endothelial cells with senescence-associated phenotypes are present in human atherosclerotic lesions, and endothelial cell senescence induced by telomere shortening may contribute to atherogenesis. ${ }^{46}$

Cellular aging results from a combination of multiple progressive cellular alterations, including accumulation of DNA damage and mutations, replicative senescence because of shortening of telomeres, and defective protein homeostasis through loss of normal proteins and accumulation of misfolded proteins. Oxidative stress and excessive growth signals (e.g., IGF) contribute to the DNA damage associated with aging. Irreversibly injured cells are removed by apoptosis; however, some cells, such as cancer cells, achieve a set of properties through mutations and epigenetic alterations. ${ }^{47}$

Some senescent cells survive and secrete proinflammatory cytokines, chemokines, proteinases, and growth factors, and influence their microenvironments; this is called the senescence-associated secretory phenotype (SASP). SASP enhances the immune response, which temporarily contributes to tissue repair and clearance of damaged cells; however, if it continues chronically, SASP promotes persistent activation of the DNA damage response, telomere attrition, and genome instability of the adjacent cells, resulting in pro-atherosclerotic or pre-carcinomatous state. ${ }^{48} \mathrm{SASP}$ is an expected common target in cancer and atherosclerosis.

Inflammation Inflammation is a common pathology in both CVD and cancer., ${ }^{\mathbf{1}}$ Inflammation mediates the progression of both atherosclerosis ${ }^{49-51}$ and colorectal cancer, ${ }^{52-56}$ with $\mathrm{C}$-reactive protein being regarded as a predictor of cardiovascular events. ${ }^{49-51}$ Several observational studies and randomized controlled trials have shown that aspirin prevents colorectal cancer. ${ }^{\mathbf{5 2 , 5 3}}$ In 2016, the US Preventive Services Task Force recommended the use of low-dose aspirin for the prevention of colorectal cancer and CVD among 50-59-year-old US adults with CVD risk factors. ${ }^{4}$ Low-dose aspirin prevented the recurrence of colon polyps in a Japanese randomized controlled trial $(\mathrm{J}-\mathrm{CAPP}){ }^{\mathbf{5 4}}$ The anti-tumorigenetic effect of aspirin is hypothesized to be modulation of prostaglandin E2, which increases cellular proliferation, promotes angiogenesis, and increases resistance to apoptosis. ${ }^{55}$ Furthermore, aspirin may play a role in $\mathrm{Wnt} / \beta$-catenin signaling, nuclear 
factor- $\kappa \mathrm{B}$ signaling, polyamine metabolism, and DNA repair. However, its preventive effect on all cancers was not accepted. In particular, its preventive effect was associated with $B R A F$-wild-type colorectal cancer but not with $B R A F$-mutated-type colorectal cancer. ${ }^{56}$ Aspirin was not effective in preventing other cancers, including cancers of the breast, prostate, and lung. ${ }^{52}$ The role of inflammation and co-factors in pathology (cytokines, growth factors, and hormones) seems different among cancer types. The Canakinumab Anti-inflammatory Thrombosis Outcomes Study (CANTOS) affirmed the inflammatory hypothesis of atherosclerosis and showed that IL-1 $\beta$, a highly specific mediator of inflammation, is a promising therapeutic target. ${ }^{57}$ Canakinumab also significantly reduced the incidence and mortality of lung cancer. The CANTOS has highlighted the role of IL- $1 \beta$ as a co-factor between cancer and atherosclerosis. ${ }^{1}$

\section{Common CVD in Cancer Patients and Survivors} AF

$\mathrm{AF}$ is the most common sustained arrhythmia in patients with cancer, with a prevalence that increases with age. ${ }^{11}$ The prevalence of AF in cancer patients aged $\geq 40$ years was $4.1 \%$ in men and $1.1 \%$ in women and was higher than the rate in the general population reported by Inoue et al. (1.4\% in men and $0.4 \%$ in women) (Figure 1) ${ }^{58} \mathrm{AF}$ is often observed in elderly patients, especially just after surgeries of the lung and esophagus. Inflammation and infection are common risk factors for cancer and AF, and cancer-derived factors might trigger $\mathrm{AF}$ in patients with cancer.,219,59

Anticoagulation therapy is important to reduce the risk of stroke in patients with $\mathrm{AF}$ without cancer. The $\mathrm{CHADS}_{2}$ and $\mathrm{CHA}_{2} \mathrm{DS}_{2}-\mathrm{VASc}$ scores are clinical predictors of the risk of thromboembolic stroke in patients with non-valvular AF (NVAF). Bleeding risk assessment can be performed using the HAS-BLED score. Quantification of the risk and benefit with these validated scores forms the basis for anticoagulation therapy in patients with NVAF in the general population. However, these scores have not been validated in cancer patients with NVAF. Cancer not only increases the risk of thromboembolism but also is often associated with a bleeding tendency. Accordingly, the decision to initiate and/or terminate antithrombotic therapy should be individualized according to the patient's characteristics. Life expectancy is essential in formulating the therapeutic strategy for $\mathrm{AF}$, and the predictors of life expectancy in Japanese patients with cancer have been provided by Iwamoto et al ${ }^{60}$ and Baba et al. ${ }^{61}$

Direct oral anticoagulants (DOACs) have favorable pharmacological properties in patients with cancer because there are less drug interactions with chemotherapeutic agents than with the vitamin $\mathrm{K}$ antagonists (VKA) ${ }^{62,63}$ DOACs have a faster onset/offset of action than the VKA and can be stopped closer to the time of a surgery and resumed soon after the bleeding risk has reduced; these properties are also favorable in patients with cancer in frequent need of invasive procedures. Although DOACs are recommended as alternatives to VKAs in patients with NVAF, ${ }^{64}$ data on the use of these drugs in patients with both NVAF and cancer are scarce. Patients with active cancer are mostly excluded in the trials of DOAC vs. VKA in NVAF patients.

In Engage TIMI-48, cancer diagnosis after randomization was not uncommon, and was independently associated with an increased risk of all-cause death and major bleeding, but not stroke or systemic embolic event. ${ }^{65}$ Patients with cancer have concerns of increased bleeding and thrombotic risks, rapid changes in renal and hepatic functions, and hematologic abnormalities. ${ }^{59,63,64}$ To avoid critical bleeding, choosing the appropriate anticoagulant agent, ${ }^{63,65,66}$ cotherapy with proton pump inhibitors in patients with risk of upper gastrointestinal tract bleeding, ${ }^{67}$ endoscopic and/ or surgical management of bleeding points, and regular follow-up by both laboratory tests and imaging are important. ${ }^{65}$ The current guidelines for AF do not provide specific recommendations for oral anticoagulation in patients with cancer. Therefore, data on the efficacy and safety of DOACs in patients with cancer and cancer AFspecific guidelines are required.

\section{HF}

LVD was observed in 2-4\% of elderly residents in Sado Island, Japan.9 ${ }^{9}$ The prevalence of LVD in patients with cancer ${ }^{11}$ may be higher than that in the general population because of the high prevalence of preexisting cardiac risk factors (e.g., hypertension, diabetes, smoking, previous LVD or HF, CAD, and age) and therapy-related risk factors (Figure 1). ${ }^{6,68}$ According to our registry, in males with cancer, although the prevalence of LVD was significantly high with hematological cancers (leukemia, lymphoma, and myeloma) and urinary bladder tumors (6-14\%), the number of cancer patients with LVD was larger for cancers of the colon, stomach, and prostate, which had an average prevalence of $2-4 \%$ and a larger number of patients. ${ }^{69}$ In females with cancer, the number of patients with LVD was larger for cancers of the breast, colon, and uterus, which had an average prevalence of $2-4 \%$.

The etiology of LVD varies among patients with different cancers; cancer therapy-related LVD, CAD, hypertension, cardiomyopathies, valvular heart diseases, and arrhythmia should be diagnosed accurately and treated concurrently with the cancer therapies. Among these etiologies, cancer therapy-related LVD influences the decisions of cancer treatment by both the patient and the cancer care provider. ${ }^{6,70,71}$ LVD has been occasionally observed in patients with cancer treated with chemotherapies for a long time (e.g., breast, colon, uterine, and hematological cancers). Anticancer agents such as anthracycline, radiation to the heart, and targeted therapies such as antihuman epidermal growth factor receptor 2 therapy (e.g., trastuzumab) are established risk factors for LVD in breast cancer and lymphoma survivors. ${ }^{\mathbf{6} 68,71}$ Particularly, LVD caused by anthracyclines is a serious complication of chemotherapy because of a significant irreversible LVD with high mortality. ${ }^{6,70-72}$ Patients with cancer at high risk of developing HF should receive medical care for strict control of CVD risk factors and comorbidities that threaten cardiac function. Otherwise, effective treatment for cancer is obliged to be withdrawn because of the risk of worsening LVD.

Beta-blockers (BBs), angiotensin-converting enzyme inhibitors (ACEI), and angiotensin-receptor blockers (ARBs) have been used in clinical trials of LVD prophylaxis in breast cancer. ${ }^{6,70,71,73-75}$ PRADA (Prevention of Cardiac Dysfunction During Adjuvant Breast Cancer Therapy) was a clinical trial that investigated primary prophylaxis of LVD with adjuvant chemotherapy (5-fluorouracil, epirubicin, and cyclophosphamide) and the patients received a combination of candesartan, metoprolol, and placebo. LVD was assessed by magnetic resonance imaging (MRI); it was 


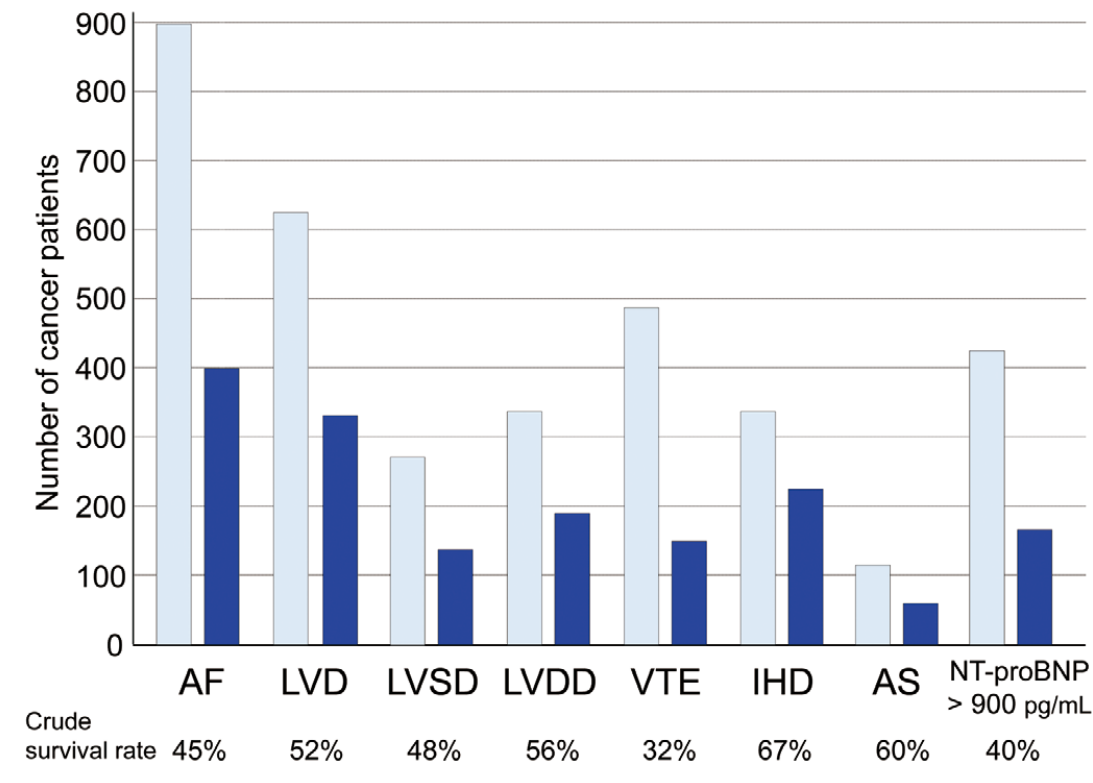

Figure 2. Number of cancer patients with CVD and the crude survival rates. The bar graphs show the total number of cancer patients in 2005-2014 (light blue) and cancer survivors in January 2015 (blue). LVD, left ventricular dysfunction. Other abbreviations as in Figure 1. Reproduced with permission from reference no. 11 .

attenuated with candesartan $(0.8 \%$ vs. $2.6 \%$ in the placebo group), but metoprolol showed no effect on the decline in the overall left ventricular ejection fraction $(\mathrm{LVEF}){ }^{73}$ The CECCY trial, which was a randomized, double-blind, placebo-controlled study that explored the role of carvedilol in the prevention of anthracycline cardiotoxicity, reported that carvedilol had no effect on the incidence of early onset of LVEF reduction. However, the use of carvedilol resulted in a significant reduction in troponin levels and diastolic dysfunction. ${ }^{74}$ In the MANTICORE (Multidisciplinary Approach to Novel Therapies in Cardio-Oncology Research) 101-Breast trial, HER2-positive patients who were treated with trastuzumab received perindopril, bisoprolol, or placebo. Trastuzumab-mediated cardiotoxicity was evaluated by MRI with increased indexed LV end-diastolic volume (LVEDVi) as the primary outcome and decreased LVEF as the secondary outcome. There was a small decline in LVEF in the placebo group (5\%), whereas the decline in LVEF was attenuated to $3 \%$ in the ACEI group and $1 \%$ in the BB group. ${ }^{75}$ However, increases in LVEDVi were not prevented by these pharmacotherapies.

Doxorubicin chemotherapy is effective for hematologic malignancies and breast cancer. The clinical indications for high-dose chemotherapy with doxorubicin include acute myeloid leukemia, Hodgkin's disease, non-Hodgkin's lymphoma, myeloma, acute lymphocytic/lymphoblastic leukemia (ALL), and advanced or relapsed breast cancer. Dexrazoxane reduces cardiac injury, as reflected by elevations in troponin $\mathrm{T}$, without compromising the antileukemic efficacy of doxorubicin in children with ALL. ${ }^{76}$ In adults, ACEIs slow the progression of LVD and prevent the development of late cardiotoxicity. ${ }^{77}$

Although pharmacological primary prevention for patients with stage A HF is controversial, the American College of Cardiology/American Heart Association guidelines for $\mathrm{HF}$ suggest treating stage $\mathrm{B} / \mathrm{C} \mathrm{HF}$ caused by anthracycline- or trastuzumab-induced cardiomyopathy. ${ }^{78}$ Earlier initiation of HF therapy at a lower New York Heart Association functional class is beneficial for LVEF recovery. ${ }^{79}$ ACEIs (or ARBs) in combination with $\mathrm{BB}$ are recommended to prevent further LVD or the development of symptomatic $\mathrm{HF}$, unless contraindicated. ${ }^{\mathbf{7 0}, 71,78,79}$

\section{VTE}

Cancer-associated VTE (cancer VTE) is a life-threatening comorbidity in patients with cancer. ${ }^{80}$ Cancer, cancer therapy (e.g., surgery, chemotherapy, and venous catheters), and a patient's predisposition to thrombophilia (e.g., age, obesity, immobility, and oral contraceptives) result in cancer VTE. ${ }^{\mathbf{1 1}, \mathbf{8 2}}$ Cancer VTE occurs frequently in patients with advanced cancer and is frequently under-recognized. The prevalence of VTE in survivors was $1.0 \%,{ }^{11}$ not as high as the prevalence in the US (4-20\%) (Figure 1). ${ }^{83}$ However, cancer VTE imposes a huge burden on patients with cancer because it is a poor prognostic factor (Figures 2,3A) and causes post-thrombotic syndrome. ${ }^{\mathbf{1 1 , 8 0}-83}$

Pulmonary thromboembolism (PTE) is the most common cause of postoperative death in cancer. ${ }^{\mathbf{8 4}}$ Screening with vascular ultrasound in all patients is not feasible because of limited medical resources. Assessment of serum D-dimer levels is used to rule out VTE and the risk-assessment model is used to evaluate VTE risk. ${ }^{85}$ Assessment of clinical pretest probability is an essential first step. D-dimer testing should not be ordered without clinical evaluation. The specificity of D-dimer testing decreases with inflammation, cancer, and recent surgery. If a patient is expected to have a positive D-dimer test in the absence of VTE, such as after major surgery, D-dimer testing should not be performed. ${ }^{\mathbf{8 5}}$ D-dimer testing is also of limited value in patients with high clinical pretest probability. Imaging tests such as vascular ultrasound and/or enhanced computed tomography should be performed immediately.

In high-risk patients undergoing major surgery, pharmacological VTE prophylaxis is recommended with an acceptable bleeding risk and mechanical prophylaxis is recommended when the bleeding risk is unacceptable. Despite these prophylaxes, VTE remains a common complication of cancer surgery; it occurred in $2.8 \%$ of 

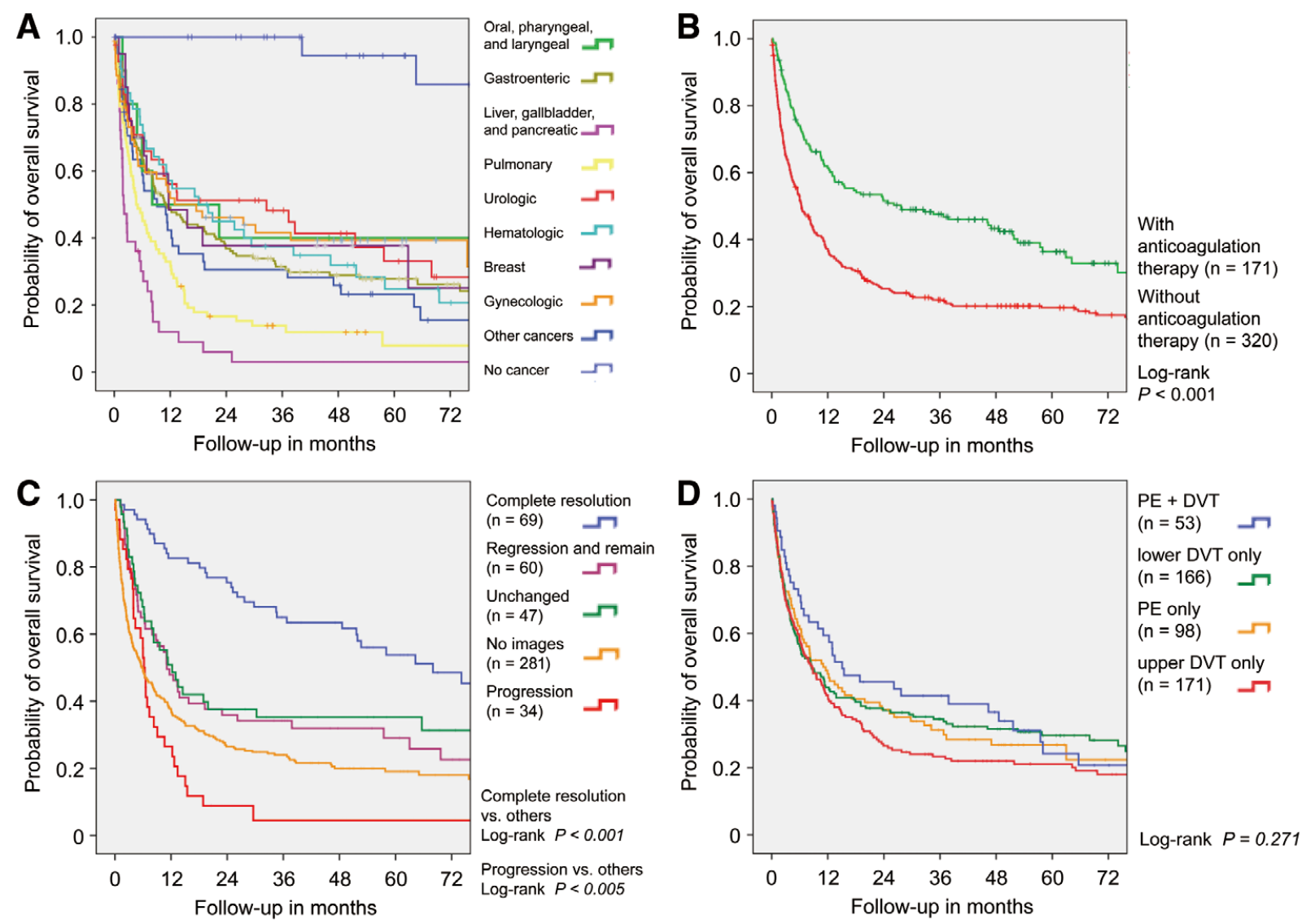

Figure 3. Kaplan-Meier estimates of overall survival in patients with venous thromboembolism (VTE) who did or did not have cancer. (A) Patients with cancer according to cancer categories (sites of cancer) and those without cancer: oral-pharyngeallaryngeal system (oral cavity, pharynges, and larynges), gastroenteric (esophagus, stomach, and colorectum), liver-gallbladderpancreatic system (liver, gallbladder, and pancreas), pulmonary, urologic (kidney, ureter, urinary bladder, and prostate), hematologic (leukemia, lymphoma, and myeloma), breast, gynecologic (uterine cervix, uterine body, and ovary), other cancers, and no cancer. (B) Overall survival in cancer patients with VTE who received or did not receive anticoagulation therapy. (C) Overall survival in cancer patients with VTE according to change in the thrombus on follow-up images. (D) Overall survival in cancer patients with VTE according to VTE site. DVT, deep vein thrombosis; PE, pulmonary embolism.

patients late after surgery and was the most common cause of death at 30 days after surgery in an Italian registry (the @ RISTOS Project). ${ }^{\mathbf{8 4}}$ Therefore, all medical staff should be aware that VTE can occur in any cancer patient after surgery regardless of age or sex. Patient education by nurses on VTE before surgery is recommended to enable both patients and nurses to identify the onset and start anticoagulation therapy immediately. ${ }^{\mathbf{8 6}}$

VTE often exposes ambulatory patients with cancer to the risk of interruption of cancer treatment and unexpected hospitalization. Recently, 2 trials of DOACs for the prevention of VTE in high-risk ambulatory patients with cancer were published ${ }^{87,88}$ Apixaban was associated with a significantly lower incidence of VTE than placebo and a higher incidence of major bleeding. ${ }^{87}$ Rivaroxaban demonstrated no statistical difference with placebo in terms of VTE incidence and major bleeding. ${ }^{\mathbf{8 8}}$ Both DOACs did not improve the overall survival in ambulatory patients with cancer. Low-molecular-weight heparin (LMWH) is believed to improve the survival of patients with early-stage cancer by preventing VTE and tumor progression; ${ }^{89}$ however, in patients with lung cancer, LMWH has no benefit in overall survival, regardless of the stage. ${ }^{\mathbf{9 0}}$

Successful control of cancer is the most effective therapy for cancer VTE. Although cancer therapies increase the risk of worsening VTE, surgical removal and/or chemo-/radiotherapy are carried out concurrently with anticoagulation therapy with acceptable bleeding risk or without anticoagulation therapy under watchful waiting until the bleeding risk subsides. LMWH has been the standard therapy for cancer VTE. ${ }^{\mathbf{7 1 , 8 6 , 8 9}}$ Hokusai VTE Cancer Investigators ${ }^{91}$ compared subcutaneous LMWH (dalteparin) and oral edoxaban, and reported no difference in the composite outcome of recurrent VTE and major bleeding. Although a higher rate of major bleeding $(6.9 \%$ vs. $4.0 \%)$ was observed in the edoxaban group, most bleeding events occurred in patients with upper gastrointestinal cancers. The SELECTD study reported a significant reduction in VTE recurrence with rivaroxaban when compared with dalteparin (4\% vs. 11\%; HR: 0.43, 95\% CI: 0.19-0.99). Similar to edoxaban, a high number of clinically relevant cases of non-major bleeding was observed with rivaroxaban (13\% vs. $4 \%$; HR: 

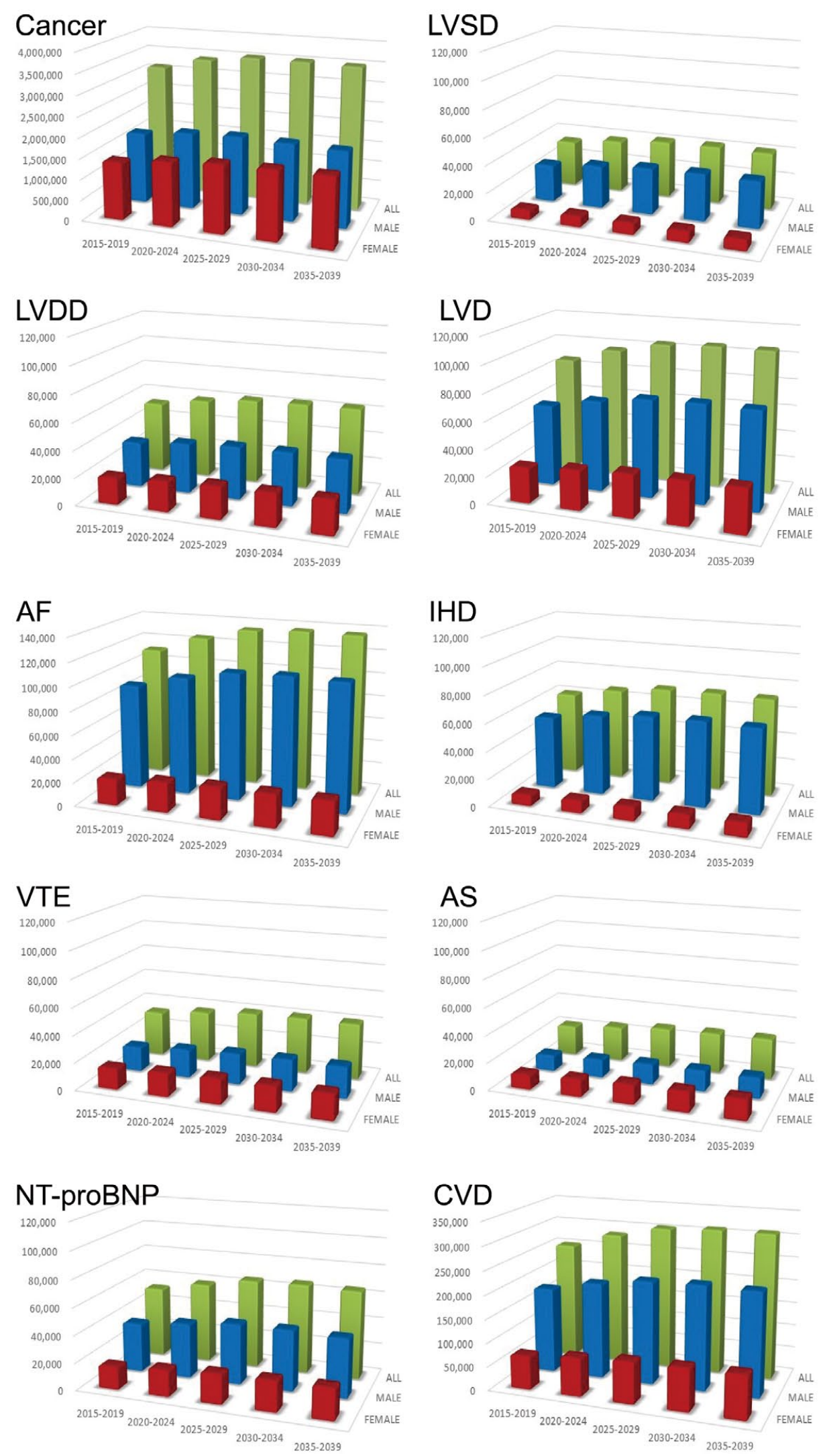

Figure 4. Projected numbers of patients with cancer between 2015 and 2039. The bar graphs show the number of patients with cancer in total and with each CVD stratified by 5-year intervals. Abbreviations as in Figures 1,2. Reproduced with permission from reference no. 69. 


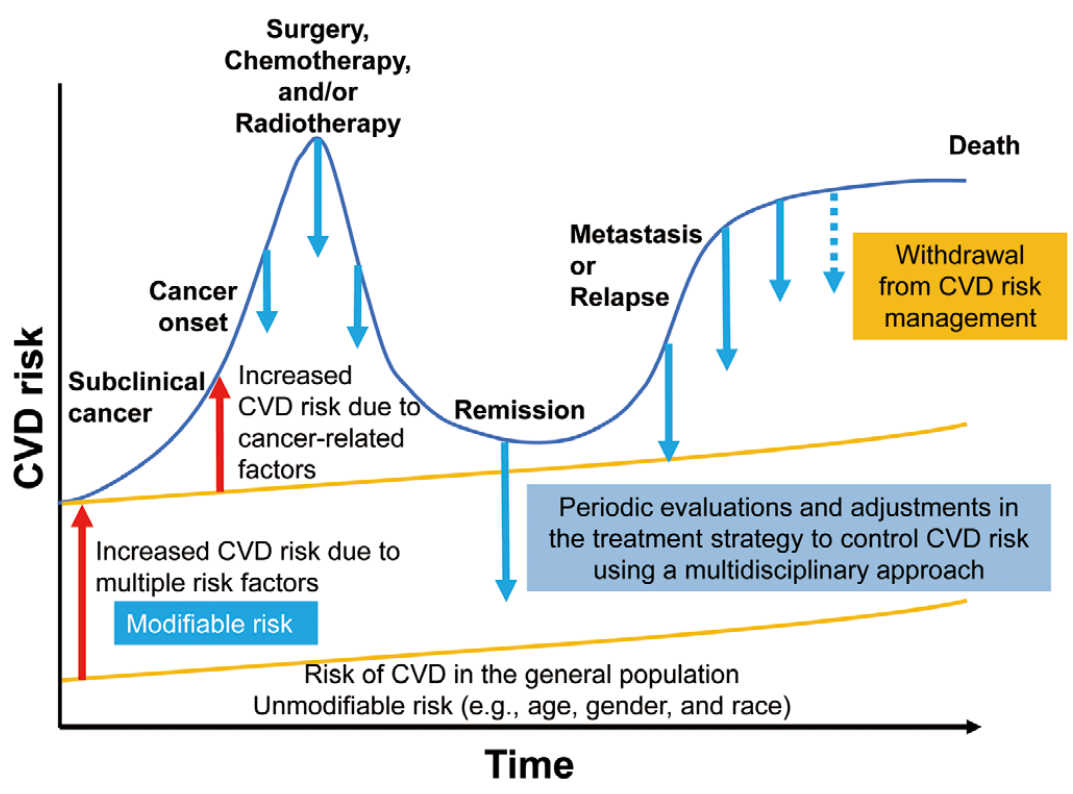

Figure 5. Changing risk of cardiovascular disease (CVD) over the clinical course of cancer and risk reduction by an onco-cardiologic approach using periodic assessments of patients' conditions and modification of treatment strategy.

3.76, 95\% CI: 1.63-8.69), especially in cancers of the upper gastrointestinal tract.92 In the guidelines of the International Society on Thrombosis and Haematosis, Khorana et al suggest the use of these DOACs in cancer patients with an acute diagnosis of VTE, a low risk of bleeding, and no drug interactions with current systemic therapy. ${ }^{93}$ Currently, a large randomized trial is ongoing to compare monotherapy with apixaban and LMWH as the initial treatment of VTE in patients with cancer. ${ }^{94}$

The COMMAND VTE Registry is a multicenter registry that has enrolled 3,027 consecutive patients with acute symptomatic VTE from 29 centers in Japan. ${ }^{95}$ Cancer patients with VTE $(n=695)$ were examined, and the cumulative 5-year incidence of recurrent VTE, major bleeding, and all-cause death was $17.7 \%, 26.6 \%$, and $73.1 \%$, respectively. Discontinuation of anticoagulation therapy was also frequent: $43.5 \%$ at 1 year. We evaluated 491 consecutive cases of cancer VTE (proximal deep vein thrombosis or PTE) for 10 years (2005-2014). ${ }^{11}$ The 5-year survival rate was $22.0 \%$ in males and $36.0 \%$ in females (log rank, $\mathrm{P}=0.025)$. Anticoagulation therapy with heparin and warfarin was started in $171(34.8 \%)$ patients, who demonstrated better survival rates than those who did not receive anticoagulation therapy (log rank, $\mathrm{P}<0.001)$ (Figure 3B). Patients with complete thrombus resolution on follow-up images had the best survival rate (Figure 3C). Cox proportional hazards analysis revealed that oral anticoagulation therapy (HR: $0.55,95 \% \mathrm{CI}: 0.42-0.72 ; \mathrm{P}<0.001$ ) and disappearance of VTE (HR: $0.42,95 \%$ CI: $0.30-0.60 ; \mathrm{P}<0.001$ ) were significantly associated with lower mortality rates. We compared the survival rate among locations of VTE (Figure 3D). PTE was not significantly associated with death (HR: 1.23, 95\% CI: 0.97-1.57; P=0.095). Anticoagulation therapy could not be initiated in the majority of patients with cancer because they were in advanced stages or had a high risk of bleeding. However, some cancer VTE patients had fair prognoses with anticoagulation therapy. DOACs may be increasingly used for various cancers in patients with cancer VTE because of their favorable effects and good drug adherence if the bleeding risk is controlled.

\section{Projection of Cancer Patients With CVD in the Future}

The number of patients with cancer in Japan is estimated to rise to approximately 3.5 million by 2025 . The disease burden may be further complicated by comorbidities caused by CVD. We used the statistics derived from the Niigata Cancer Center CVD Study (2015), as well as the population estimates from the National Cancer Center's Cancer Registry and Statistics survey of 2017 for future projections of onco-cardiology (Figure 4).11,16,69 The total number of Japanese cancer patients with CVD was 253,000 in 2015 and is predicted to rapidly increase by 30,000 by 2020 and demonstrate a peak of 313,000 during 2030 2034. ${ }^{69}$ The CVD population will predominately include men, with a 2.5 -fold higher number than women. The growth rate of the population with both cancer and CVD will be greater than that of the cancer-only population (1.23 vs. $1.18, \mathrm{P}<0.001)$ and will notably comprise high proportions of patients with prostatic, breast, and uterine cancers $(1.80,1.57$, and $1.66, \mathrm{P}<0.001$, respectively). Future cancer patients will be older and more likely to have CVD. Although men will continue to be predominately affected, the increase in the number of women will also be pronounced. Cancer care providers should be trained to recognize CVD and provide any necessary interventions concurrently with cancer therapy.

\section{Individualized Treatment for Cancer Patients With CVD}

Cardiologists see cancer patients with varying prognoses at various stages, phases of treatments, and performance status. Patients with cancer have concerns of increased risks of bleeding and thrombosis, rapid changes in renal and hepatic functions, hematologic abnormalities, and potential for chemotherapeutic agent interactions. Therefore, 
periodic assessments of their conditions and modification of treatment strategy are indispensable (Figure 5). The elevated CVD risk derives from cancer-related factors and accumulation of CVD risk factors, such as smoking, obesity, diabetes, hypertension, and physical inactivity. ${ }^{\mathbf{9}}$ The American Heart Association suggested the development of a cardio-oncology rehabilitation program for the prevention of CVD. ${ }^{97}$ To individualize management, cardiologists should understand the epidemiology, natural history, and clinical course following various cancer therapies. Decision-making with patients is standard. For example, the decision to initiate or withdraw antithrombotic therapy should be individualized based on patient's characteristics while incorporating the patient's preferences and values.

\section{Future Perspectives}

The field of cardio-oncology continues to evolve with progress in both oncology and cardiology. The need for dedicated cardiovascular care of patients with cancer will continue to grow to maximize the oncologic effectiveness and minimize the cardiotoxic potential. A framework for collaboration among patients, cardiologists, interventionalists, ${ }^{98}$ oncologists, industry partners, and officials is needed to address the gaps between knowledge and practice for personalized care. Evidence-based medicine and CVD guidelines for patients with cancer will be crucial in the future.

\section{Acknowledgment}

We are indebted to the staff of the Department of Cardiology at the Niigata University Medical and Dental Hospital for Cardiovascular Emergency of Cancer Patients.

\section{References}

1. Ridker PM, MacFadyen JG, Thuren T, Everett BM, Libby P, Glynn RJ; CANTOS Trial Group. Effect of interleukin- $1 \beta$ inhibition with canakinumab on incident lung cancer in patients with atherosclerosis: Exploratory results from a randomised, double-blind, placebo-controlled trial. Lancet 2017; 390: 18331842 .

2. Koene RJ, Prizment AE, Blaes A, Konety SH. Shared risk factors in cardiovascular disease and cancer. Circulation 2016; 133: $1104-1114$.

3. Handy CE, Quispe R, Pinto X, Blaha MJ, Blumenthal RS, Michos ED, et al. Synergistic opportunities in the interplay between cancer screening and cardiovascular disease risk assessment. Circulation 2018; 138: 727-734.

4. Bibbins-Domingo K; U.S. Preventive Services Task Force. Aspirin use for the primary prevention of cardiovascular disease and colorectal cancer: U.S. Preventive Services Task Force Recommendation Statement. Ann Intern Med 2016; 164: 836-845.

5. Bonnie KY. Cardio-oncology. In: Braunwald E, editor. Heart disease, 11th edn. Philadelphia: Saunders, 2018; 1641-1650.

6. Mehta LS, Watson KE, Barac A, Beckie TM, Bittner V, CruzFlores $\mathrm{S}$, et al. Cardiovascular disease and breast cancer: Where these entities intersect: A scientific statement from the American Heart Association. Circulation 2018; 137: e30-e66.

7. 5-year prevalence of all cancers by age group in Estimates of Cancer Prevalence (Topics 4). In: Wakao F, editor. CANCER STATISTICS IN JAPAN 2017. Tokyo: Foundation for Promotion of Cancer Research (FPCR), 2018; 125. https://ganjoho.jp/en/ professional/statistics/brochure/2017_en.html (accessed September $6,2019)$.

8. National Comprehensive Cancer Network. NCCN Clinical Practice Guidelines in Oncology (NCCN Guidelines): Older Adult Oncology. https://www.nccn.org/professionals/physician_gls/ default.aspx\#detection (accessed September 6, 2019).

9. Okura Y, Ohno Y, Ramadan MM, Suzuki K, Taneda K, Obata $\mathrm{H}$, et al. Characterization of outpatients with isolated diastolic dysfunction and evaluation of the burden in a Japanese community: Sado Heart Failure Study. Circ J 2007; 71: 1013-1021.

10. Edwards BK, Noone AM, Mariotto AB, Simard EP, Boscoe FP, Henley SJ, et al. Annual report to the nation on the status of cancer, 1975-2010, featuring prevalence of comorbidity and impact on survival among persons with lung, colorectal, breast, or prostate cancer. Cancer 2014; 120: 1290-1314.

11. Okura Y, Takayama T, Ozaki K, Tanaka H, Seki H, Takenouchi $\mathrm{T}$, et al. Burden of cardiovascular disease on Japanese cancer patients and survivors: A single cancer-center study in Niigata City. Int J Clin Oncol 2019; 24: 196-210.

12. Sueta D, Hokimoto S, Utsunomiya D, Tabata N, Akasaka T, Sakamoto K, et al. New aspects of onco-cardiology. Int J Cardiol 2016; 206: $68-70$.

13. Navi BB, Reiner AS, Kamel H, Iadecola C, Okin PM, Elkind MSV, et al. Risk of arterial thromboembolism in patients with cancer. J Am Coll Cardiol 2017; 70: 926-938.

14. American Cancer Society. Cancer Facts \& Figures 2017. ACS, Atlanta. https://www.cancer.org/research/cancer-facts-statistics/ all-cancer-facts-figures/cancer-facts-figures-2017.html (accessed September 6, 2019).

15. Mortality by cause of death. Statistics Bureau, Ministry of internal affairs and communications. http://www.stat.go.jp/data/ sekai/0116.htm\#c14 (accessed September 6, 2019).

16. Trends in 5-year survival rate, data from population-based cancer registry (Diagnosed in 1993-1996, 1997-1999, 2000-2002, 20032005, 2006-2008). In: Wakao F, editor. CANCER STATISTICS IN JAPAN 2018. Tokyo: Foundation for Promotion of Cancer Research (FPCR), 2019; 54. https://ganjoho.jp/en/professional/ statistics/brochure/2018_en.html (accessed September 6, 2019).

17. Eyre H, Kahn R, Robertson RM, Clark NG, Doyle C, Hong Y, et al. Preventing cancer, cardiovascular disease, and diabetes: A common agenda for the American Cancer Society, the American Diabetes Association, and the American Heart Association. Circulation 2004; 109: 3244-3255.

18. Navi BB, Reiner AS, Kamel H, Iadecola C, Okin PM, Tagawa ST, et al. Arterial thromboembolic events preceding the diagnosis of cancer in older persons. Blood 2019; 133: 781-789.

19. Vinter N, Christesen AMS, Fenger-Grøn M, Tjønneland A, Frost L. Atrial fibrillation and risk of cancer: A Danish populationbased cohort study. J Am Heart Assoc 2018; 7: e009543.

20. Hasin T, Gerber Y, McNallan SM, Weston SA, Kushwaha SS, Nelson TJ, et al. Patients with heart failure have an increased risk of incident cancer. J Am Coll Cardiol 2013; 62: 881-886.

21. van Es N, Le Gal G, Otten HM, Robin P, Piccioli A, Lecumberri $\mathrm{R}$, et al. Screening for occult cancer in patients with unprovoked venous thromboembolism: A systematic review and meta-analysis of individual patient data. Ann Intern Med 2017; 167: 410-417.

22. National Cancer Center Japan. Ten years survival of cancer patients in hospital group of Japanese Association of Clinical Cancer Centers [Press release, April 9, 2019]. https://www.ncc. go.jp/jp/information/pr_release/2019/0409/index.html (accessed September 6, 2019).

23. Minami M, Matsumoto S, Horiuchi H. Cardiovascular side-effects of modern cancer therapy. Circ J 2010; 74: 1779-1786.

24. Floyd JD, Nguyen DT, Lobins RL, Bashir Q, Doll DC, Perry MC. Cardiotoxicity of cancer therapy. J Clin Oncol 2005; 23: $7685-7696$.

25. Timp JF, Braekkan SK, Versteeg HH, Cannegieter SC. Epidemiology of cancer-associated venous thrombosis. Blood 2013; 122: $1712-1723$.

26. Armenian SH, Xu L, Ky B, Sun C, Farol LT, Pal SK, et al. Cardiovascular disease among survivors of adult-onset cancer: A community-based retrospective cohort study. J Clin Oncol 2016; 34: $1122-1130$.

27. Younus A, Aneni EC, Spatz ES, Osondu CU, Roberson L, Ogunmoroti $\mathrm{O}$, et al. A systematic review of the prevalence and outcomes of ideal cardiovascular health in US and non-US populations. Mayo Clin Proc 2016; 91: 649-670.

28. Sasazuki S, Inoue M, Iwasaki M, Sawada N, Shimazu T, Yamaji $\mathrm{T}$, et al; JPHC Study Group. Combined impact of five lifestyle factors and subsequent risk of cancer: The Japan Public Health Center Study. Prev Med 2012; 54: 112-116.

29. Hecht SS. Tobacco carcinogens, their biomarkers and tobaccoinduced cancer. Nat Rev Cancer 2003; 3: 733-744.

30. Alexandrov LB, Ju YS, Haase K, Van Loo P, Martincorena I, Nik-Zainal S, et al. Mutational signatures associated with tobacco smoking in human cancer. Science 2016; 354: 618-622.

31. Steppan CM, Bailey ST, Bhat S, Brown EJ, Banerjee RR, Wright $\mathrm{CM}$, et al. The hormone resistin links obesity to diabetes. Nature 
2001; 409: 307-312.

32. Kasuga M. Insulin resistance and pancreatic beta cell failure. $J$ Clin Invest 2006; 116: 1756-1760.

33. Renehan AG, Zwahlen M, Egger M. Adiposity and cancer risk: New mechanistic insights from epidemiology. Nat Rev Cancer 2015; 15: 484-498.

34. Lauby-Secretan B, Scoccianti C, Loomis D, Grosse Y, Bianchini F, Straif K. Body fatness and cancer: Viewpoint of the IARC Working Group. N Engl J Med 2016; 375: 794-798.

35. Schmidt S, Monk JM, Robinson LE, Mourtzakis M. The integrative role of leptin, oestrogen and the insulin family in obesity-associated breast cancer: Potential effects of exercise. Obes Rev 2015; 16: 473-487.

36. Rasmussen-Torvik LJ, Shay CM, Abramson JG, Friedrich CA, Nettleton JA, Prizment AE, et al. Ideal cardiovascular health is inversely associated with incident cancer: The Atherosclerosis Risk in Communities study. Circulation 2013; 127: 1270-1275.

37. Tsilidis KK, Kasimis JC, Lopez DS, Ntzani EE, Ioannidis JP. Type 2 diabetes and cancer: Umbrella review of meta-analyses of observational studies. BMJ 2015; 350: g7607.

38. Renehan AG, Zwahlen M, Minder C, O'Dwyer ST, Shalet SM, Egger M. Insulin-like growth factor (IGF)-I, IGF binding protein-3, and cancer risk: Systematic review and meta-regression analysis. Lancet 2004; 363: 1346-1353.

39. Goto A, Noto H, Noda M, Ueki K, Kasuga M, Tajima N, et al. Report of the Japan Diabetes Society (JDS)/Japanese Cancer Association (JCA) joint committee on diabetes and cancer, second report. Diabetol Int 2016; 7: 12-15.

40. Sasazuki S, Charvat H, Hara A, Wakai K, Nagata C, Nakamura $\mathrm{K}$, et al; Research group for the development and evaluation of cancer prevention strategies in Japan. Diabetes mellitus and cancer risk: Pooled analysis of eight cohort studies in Japan. Cancer Sci 2013; 104: 1499-1507.

41. Goto A, Yamaji T, Sawada N, Momozawa Y, Kamatani Y, Kubo M, et al. Diabetes and cancer risk: A Mendelian randomization study. Int J Cancer, doi:10.1002/ijc.32310.

42. Harding JL, Sooriyakumaran M, Anstey KJ, Adams R, Balkau B, Brennan-Olsen S, et al. Hypertension, antihypertensive treatment and cancer incidence and mortality: A pooled collaborative analysis of 12 Australian and New Zealand cohorts. J Hypertens 2016; 34: 149-155.

43. Stocks T, Van Hemelrijck M, Manjer J, Bjørge T, Ulmer H, Hallmans $\mathrm{G}$, et al. Blood pressure and risk of cancer incidence and mortality in the Metabolic Syndrome and Cancer Project. Hypertension 2012; 59: 802-810.

44. Driver JA, Djoussé L, Logroscino G, Gaziano JM, Kurth T. Incidence of cardiovascular disease and cancer in advanced age: Prospective cohort study. BMJ 2008; 337: a2467.

45. Minamino T, Miyauchi $\mathrm{H}$, Yoshida $\mathrm{T}$, Ishida $\mathrm{Y}$, Yoshida $\mathrm{H}$, Komuro I. Endothelial cell senescence in human atherosclerosis: Role of telomere in endothelial dysfunction. Circulation 2002; 105: $1541-1544$.

46. Minamino T, Komuro I. Vascular cell senescence: Contribution to atherosclerosis. Circ Res 2007; 100: 15-26.

47. Cellular aging. In: Vinay Kumar V, Abbas AK, Aster JC, editors. Robbins basic pathology, 10th edn. Philadelphia: Elsevier, 2018; $54-56$.

48. Ohtani N, Hara E. Roles and mechanisms of cellular senescence in regulation of tissue homeostasis. Cancer Sci 2013; 104: $525-530$.

49. Ridker PM, Cushman M, Stampfer MJ, Tracy RP, Hennekens $\mathrm{CH}$. Inflammation, aspirin, and the risk of cardiovascular disease in apparently healthy men. $N$ Engl J Med 1997; 336: 973-979.

50. Ross R. The pathogenesis of atherosclerosis: A perspective for the 1990s. Nature 1993; 362: 801-809.

51. Tabata N, Sueta D, Yamamoto E, Takashio S, Arima Y, Araki S; KUMA study investigators. Outcome of current and history of cancer on the risk of cardiovascular events following percutaneous coronary intervention: A Kumamoto University Malignancy and Atherosclerosis (KUMA) study. Eur Heart J Qual Care Clin Outcomes 2018; 4: 290-300.

52. Cao Y, Nishihara R, Wu K, Wang M, Ogino S, Willett WC J, et al. Population-wide impact of long-term use of aspirin and the risk for cancer. JAMA Oncol 2016; 2: 762-769.

53. Dulai PS, Singh S, Marquez E, Khera R, Prokop LJ, Limburg $\mathrm{PJ}$, et al. Chemoprevention of colorectal cancer in individuals with previous colorectal neoplasia: Systematic review and network meta-analysis. $B M J$ 2016; 355: i6188.

54. Ishikawa H, Mutoh M, Suzuki S, Tokudome S, Saida Y, Abe T, et al. The preventive effects of low-dose enteric-coated aspirin tablets on the development of colorectal tumors in Asian patients: A randomized trial. Gut 2014; 63: 1755-1759.

55. Drew DA, Cao Y, Chan AT. Aspirin and colorectal cancer: The promise of precision chemoprevention. Nat Rev Cancer 2016; 16: $173-186$.

56. Nishihara R, Lochhead P, Kuchiba A, Jung S, Yamauchi M, Liao X, et al. Aspirin use and risk of colorectal cancer according to BRAF mutation status. JAMA 2013; 309: 2563-2571.

57. Ridker PM, Everett BM, Thuren T, MacFadyen JG, Chang WH, Ballantyne C, et al; CANTOS Trial Group. Antiinflammatory therapy with canakinumab for atherosclerotic disease. $N$ Engl $J$ Med 2017; 377: 1119-1131.

58. Inoue H, Fujiki A, Origasa H, Ogawa S, Okumura K, Kubota I, et al. Prevalence of atrial fibrillation in the general population of Japan: An analysis based on periodic health examination. Int $J$ Cardiol 2009; 137: $102-107$.

59. Farmakis D, Parissis J, Filippatos G. Insights into onco-cardiology: Atrial fibrillation in cancer. J Am Coll Cardiol 2014; 63: 945-953.

60. Iwamoto M, Nakamura F, Higashi T. Estimated life expectancy and risk of death from cancer by quartiles in the older Japanese population: 2010 vital statistics. Cancer Epidemiol 2014; 38: $511-514$.

61. Baba M, Maeda I, Morita T, Inoue S, Ikenaga M, Matsumoto $Y$, et al. Survival prediction for advanced cancer patients in the real world: A comparison of the Palliative Prognostic Score, Delirium-Palliative Prognostic Score, Palliative Prognostic Index and modified Prognosis in Palliative Care Study predictor model. Eur J Cancer 2015; 51: 1618-1629.

62. Wessler JD, Grip LT, Mendell J, Giugliano RP. The P-glycoprotein transport system and cardiovascular drugs. J Am Coll Cardiol 2013; 61: 2495-2502.

63. Shah S, Norby FL, Datta YH, Lutsey PL, MacLehose RF, Chen LY, et al. Comparative effectiveness of direct oral anticoagulants and warfarin in patients with cancer and atrial fibrillation. Blood Adv 2018; 2: 200-209.

64. JCS Joint Working Group. Guidelines for pharmacotherapy of atrial fibrillation (JCS 2013): Digest version. Circ J 2014; 78: 1997-2021.

65. Fanola CL, Ruff CT, Murphy SA, Jin J, Duggal A, Babilonia NA, et al. Efficacy and safety of edoxaban in patients with active malignancy and atrial fibrillation: Analysis of the ENGAGE AF-TIMI 48 Trial. J Am Heart Assoc 2018; 7: e008987.

66. Lowenstern A, Al-Khatib SM, Sharan L, Chatterjee R, Allen LaPointe NM, Shah B, et al. Interventions for preventing thromboembolic events in patients with atrial fibrillation: A systematic review. Ann Intern Med 2018; 169: 774-787.

67. Ray WA, Chung CP, Murray KT, Smalley WE, Daugherty JR, Dupont WD, et al. Association of oral anticoagulants and proton pump inhibitor cotherapy with hospitalization for upper gastrointestinal tract bleeding. JAMA 2018; 320: 2221-2230.

68. Bloom MW, Hamo CE, Cardinale D, Ky B, Nohria A, Baer L, et al. Cancer therapy-related cardiac dysfunction and heart failure. Part 1: Definitions, pathophysiology, risk factors, and imaging. Circ Heart Fail 2016; 9: e002661.

69. Okura Y, Takayama T, Ozaki K, Tanaka H, Kikuchi A, Saito $\mathrm{T}$, et al. Future projection of cancer patients with cardiovascular disease in Japan by the year 2039: A pilot study. Int J Clin Oncol 2019; 24: 983-994.

70. Hamo CE, Bloom MW, Cardinale D, Ky B, Nohria A, Baer L, et al. Cancer therapy-related cardiac dysfunction and heart failure. Part 2: Prevention, treatment, guidelines, and future directions. Circ Heart Fail 2016; 9: e002843.

71. Zamorano JL, Lancellotti P, Rodriguez Muñoz D, Aboyans V, Asteggiano R, Galderisi M, et al. 2016 ESC Position Paper on cancer treatments and cardiovascular toxicity developed under the auspices of the ESC Committee for Practice Guidelines: The Task Force for Cancer Treatments and Cardiovascular Toxicity of the European Society of Cardiology (ESC). Eur Heart J 2016; 37: $2768-2801$.

72. Felker GM, Thompson RE, Hare JM, Hruban RH, Clemetson DE, Howard DL, et al. Underlying causes and long-term survival in patients with initially unexplained cardiomyopathy. $N$ Engl $J$ Med 2000; 342: 1077-1084.

73. Gulati G, Heck SL, Ree AH, Hoffmann P, Schulz-Menger J, Fagerland MW, et al. Prevention of cardiac dysfunction during adjuvant breast cancer therapy (PRADA): A $2 \times 2$ factorial, randomized, placebo-controlled, double-blind clinical trial of candesartan and metoprolol. Eur Heart J 2016; 37: 1671 - 1680.

74. Avila MS, Ayub-Ferreira SM, de Barros Wanderley MR Jr, das Dores Cruz F, Gonçalves Brandão SM, Rigaud VOC, et al. 
Carvedilol for prevention of chemotherapy-related cardiotoxicity: The CECCY trial. J Am Coll Cardiol 2018; 71: 2281-2290.

75. Pituskin E, Mackey JR, Koshman S, Jassal D, Pitz M, Haykowsky $\mathrm{MJ}$, et al. Multidisciplinary approach to novel therapies in cardio-oncology research (MANTICORE 101-Breast): A randomized trial for the prevention of trastuzumab-associated cardiotoxicity. J Clin Oncol 2017; 35: 870-877.

76. Lipshultz SE, Rifai N, Dalton VM, Levy DE, Silverman LB, Lipsitz SR, et al. The effect of dexrazoxane on myocardial injury in doxorubicin-treated children with acute lymphoblastic leukemia. $N$ Engl J Med 2004; 351: 145-153.

77. Cardinale D, Colombo A, Sandri MT, Lamantia G, Colombo N, Civelli M, et al. Prevention of high-dose chemotherapy-induced cardiotoxicity in high-risk patients by angiotensin-converting enzyme inhibition. Circulation 2006; 114: 2474-2481.

78. Yancy CW, Jessup M, Bozkurt B, Butler J, Casey DE Jr, Colvin MM, et al. 2017 ACC/AHA/HFSA focused update of the 2013 ACCF/AHA guideline for the management of heart failure: A report of the American College of Cardiology/American Heart Association Task Force on Clinical Practice Guidelines and the Heart Failure Society of America. Circulation 2017; 136: e137e161.

79. Cardinale D, Colombo A, Lamantia G, Colombo N, Civelli M, De Giacomi G, et al. Anthracycline-induced cardiomyopathy: Clinical relevance and response to pharmacologic therapy. $J \mathrm{Am}$ Coll Cardiol 2010; 55: 213-220.

80. Khorana AA, Francis CW, Culakova E, Kuderer NM, Lyman $\mathrm{GH}$. Thromboembolism is a leading cause of death in cancer patients receiving outpatient chemotherapy. J Thromb Haemost 2007; 5: 632-634.

81. Khorana AA, Connolly GC. Assessing risk of venous thromboembolism in the patient with cancer. J Clin Oncol 2009; 27: $4839-4847$

82. Ashrani AA, Gullerud RE, Petterson TM, Marks RS, Bailey KR, Heit JA. Risk factors for incident venous thromboembolism in active cancer patients: A population based case-control study. Thromb Res 2016; 139: 29-37.

83. Chew HK, Wun T, Harvey D, Zhou H, White RH. Incidence of venous thromboembolism and its effect on survival among patients with common cancers. Arch Intern Med 2006; 166: 458464.

84. Agnelli G, Bolis G, Capussotti L, Scarpa RM, Tonelli F, Bonizzoni E, et al. A clinical outcome-based prospective study on venous thromboembolism after cancer surgery: The @RISTOS Project. Ann Surg 2006; 243: 89-95.

85. Kearon C. Diagnosis of suspected venous thromboembolism. Hematol Am Soc Hematol Educ Program 2016; 2016: 397-403.

86. Lyman GH, Bohlke K, Khorana AA, Kuderer NM, Lee AY, Arcelus JI, et al. Venous thromboembolism prophylaxis and treatment in patients with cancer: American Society of Clinical Oncology Clinical Practice Guideline update 2014. J Clin Oncol 2015; 33: 654-656.

87. Carrier M, Abou-Nassar K, Mallick R, Tagalakis V, Shivakumar
S, Schattner A, et al; AVERT Investigators. Apixaban to prevent venous thromboembolism in patients with cancer. $N$ Engl J Med 2019; 380: 711-719.

88. Khorana AA, Soff GA, Kakkar AK, Vadhan-Raj S, Riess H, Wun T, et al; CASSINI Investigators. Rivaroxaban for thromboprophylaxis in high-risk ambulatory patients with cancer. $N$ Engl J Med 2019; 380: 720-728.

89. Lee AY, Rickles FR, Julian JA, Gent M, Baker RI, Bowden C, et al. Randomized comparison of low molecular weight heparin and coumarin derivatives on the survival of patients with cancer and venous thromboembolism. J Clin Oncol 2005; 23: $2123-$ 2129.

90. Macbeth F, Noble S, Evans J, Ahmed S, Cohen D, Hood K, et al. Randomized phase III trial of standard therapy plus low molecular weight heparin in patients with lung cancer: FRAGMATIC Trial. J Clin Oncol 2016; 34: 488-494.

91. Raskob GE, van Es N, Verhamme P, Carrier M, Di Nisio M, Garcia D, et al; Hokusai VTE Cancer Investigators. Edoxaban for the treatment of cancer-associated venous thromboembolism. N Engl J Med 2018; 378: 615-624.

92. Young AM, Marshall A, Thirlwall J, Chapman O, Lokare A, Hill C, et al. Comparison of an oral factor Xa inhibitor with low molecular weight heparin in patients with cancer with venous thromboembolism: Results of a randomized trial (SELECT-D). J Clin Oncol 2018; 36: 2017-2023.

93. Khorana AA, Noble S, Lee AYY, Soff G, Meyer G, O'Connell $\mathrm{C}$, et al. Role of direct oral anticoagulants in the treatment of cancer-associated venous thromboembolism: Guidance from the SSC of the ISTH. J Thromb Haemost 2018; 16: 1891-1894.

94. Agnelli G, Becattini C, Bauersachs R, Brenner B, Campanini M, Cohen A, et al; Caravaggio Study Investigators. Apixaban versus dalteparin for the treatment of acute venous thromboembolism in patients with cancer: The Caravaggio Study. Thromb Haemost 2018; 118: $1668-1678$.

95. Yamashita Y, Morimoto T, Amano H, Takase T, Hiramori S, Kim K, et al; COMMAND VTE Registry Investigators. Anticoagulation therapy for venous thromboembolism in the real world: From the COMMAND VTE registry. Circ $J$ 2018; 82: $1262-$ 1270

96. Weaver KE, Foraker RE, Alfano CM, Rowland JH, Arora NK, Bellizzi KM, et al. Cardiovascular risk factors among long-term survivors of breast, prostate, colorectal, and gynecologic cancers: A gap in survivorship care? J Cancer Surviv 2013; 7: 253-261

97. Gilchrist SC, Barac A, Ades PA, Alfano CM, Franklin BA, Jones LW, et al. Cardio-oncology rehabilitation to manage cardiovascular outcomes in cancer patients and survivors: A scientific statement from the American Heart Association. Circulation 2019; 139: e997-e1012.

98. Liu VY, Agha AM, Lopez-Mattei J, Palaskas N, Kim P, Thompson $\mathrm{K}$, et al. Interventional cardio-oncology: Adding a new dimension to the cardio-oncology field. Front Cardiovasc Med 2018; 5: 48. 